\title{
FACTORS, INCREASING THE EFFICIENCY OF WORK OF MAINTENANCE, REPAIR AND OPERATION UNITS OF INDUSTRIAL ENTERPRISES
}

\author{
Marek KRYNKE \\ Czestochowa University of Technology \\ Tatiana N. IVANOVA \\ Tchaikovsky Branch "Perm National Research Polytechnic Institute" \\ Federal State Budgetary Institution of Science \\ "Udmurt Federal Research Center of the Ural Branch of the Russian Academy of Sciences" \\ Nicolay F. REVENKO \\ Autonomous Noncommercial Organization "Study Accreditation Center"
}

\begin{abstract}
:
The article contains the analysis of factors influencing the efficiency of work of equipment maintenance, repair and operation (MRO) units of industrial enterprises. We have systematized various classifications of these factors, which were proposed in economic literature by different authors. We have divided the factors into following groups: general and local; primary and secondary; external and internal; major and non-essential; direct and oblique; reducing and boosting the expenses on equipment MRO and repair cost; production and non-production; depending on management and independent; economic, operation, organization ones; structural and production-technical ones; which are interconnected. It has been proposed to classify factors influencing the efficiency of equipment MRO units into five groups: economic, exploitation, organization, production-technical and structural ones. Using expert evaluation method, the factors have been divided into three groups according to degree of their influence on efficiency of work of equipment MRO units of industrial enterprises. The priority was given to the factors of the first group, having decisive influence on formation of efficiency. The most significant factors have been identified. In opinion of experts, these factors include: method of organization of work of equipment MRO service; level of economic autonomy of MRO enterprise in terms of organization of equipment MRO; financial and market situation of enterprise; the degree of repair complexity of production equipment.
\end{abstract}

Key words: maintenance, repair and operation (MRO), method of organization of work of equipment MRO service; level of economic autonomy of MRO enterprise

\section{INTRODUCTION}

Analysis of the growth of the efficiency of operations of maintenance, repair and operation (MRO) units of industrial enterprise allows finding out the factors or the sources of this process. It is accepted to understand the factors of efficiency of works of equipment maintenance, repair and operation (MRO) as the processes and phenomena, which determine the scale of production output increase and possibilities of growth of optimum efficiency of work of equipment MRO and the whole enterprise itself. For example, Z.B. Khmelnitskaya has noted: "Depending on the whole range of technical, economic and organization factors, the system of technical maintenance (including repair services) can be transformed in terms of its composition, volume and nomenclature of services" [1]. One way or another, the change in consumption of particular types of resources inevitably causes the change in parameters of efficient work of MRO units of industrial enterprises.

An overview of economic literature has shown that different authors offer various classifications of factors, influencing the efficiency of work of MRO service units of enterprise $[2,3,4,5,6,7,8,9,10,11,12]$.

Generalization and systematization of gained experience allows offering the classification, according to which the factors $[13,14]$, influencing the efficiency of technical 
maintenance and repair of equipment on industrial services [15], are divided into general and local, primary and secondary [16, 17], major and non-essential, direct and oblique [18, 19, 20, 21, 22], etc. (Table 1).

Table 1

Systematization of factors, influencing the efficiency of work of maintenance, repair and operation service units (according

to the major criteria)

\begin{tabular}{|c|c|}
\hline Classification criteria & $\begin{array}{c}\text { Division of factors } \\
\text { according to the criterion }\end{array}$ \\
\hline Action source & $\begin{array}{l}\text { External } \\
\text { Intra-plant }\end{array}$ \\
\hline $\begin{array}{l}\text { Method of action on efficiency } \\
\text { of MRO of equipment }\end{array}$ & $\begin{array}{l}\text { Direct } \\
\text { Oblique }\end{array}$ \\
\hline $\begin{array}{l}\text { Influence of supervising } \\
\text { personnel on the factor }\end{array}$ & $\begin{array}{l}\text { Objective } \\
\text { Subjective }\end{array}$ \\
\hline $\begin{array}{l}\text { Influence on the expenses } \\
\text { on MRO of equipment }\end{array}$ & $\begin{array}{l}\text { Reducing } \\
\text { Boosting }\end{array}$ \\
\hline $\begin{array}{l}\text { Possibility of quantitative } \\
\text { assessment }\end{array}$ & $\begin{array}{l}\text { Complicated } \\
\text { Certain }\end{array}$ \\
\hline $\begin{array}{l}\text { Influence on the cost } \\
\text { of equipment MRO works }\end{array}$ & $\begin{array}{l}\text { Reducing } \\
\text { Boosting }\end{array}$ \\
\hline Groups of factors & $\begin{array}{l}\text { Economic } \\
\text { Operation } \\
\text { Organization } \\
\text { Structural } \\
\text { Production-technical }\end{array}$ \\
\hline
\end{tabular}

Some of them influence the degree of use of all-type resources during equipment MRO, thus increasing the performance efficiency of enterprise. The others mainly affect the consumption of particular types of resources, for example, equipment technical state, operation conditions, quality of used structural materials, durability of parts and overhaul life. However, these factors also influence the efficiency of use of other resources indirectly.

\section{EFFICIENCY OF WORK OF EQUIPMENT MAINTENANCE - ANALYSIS}

Efficiency of equipment MRO on industrial enterprises is formed under the action of several factors. They include: the resources, used in production (production assets, labor resources), organization and economic form of their use and the complex of industrial relations between the state and industrial enterprises, between separate enterprises, between the personnel of industrial enterprise and a particular worker. Consequently, the efficiency of equipment MRO on industrial enterprises is formed under the action of big range of factors, causes and circumstances, including those, which are hard to predict (sudden accident failures of equipment).

Some of them can be expressed quantitatively and compared with specific result of economic management. The other group cannot be compared to such effect. Separate processes of equipment MRO can have accidental errors. These include repair period, set of repair operations, quality of replacement parts, availability of means for mechanization of repair operations, working personnel qualification. They all influence the production costs of equipment MRO and, eventually, the value of gross income and profit of the enterprise. To reflect the influence of the whole range of factors adequately, it is necessary to use systematized approach and different methods of analysis.

In addition, depending on the action on efficiency of MRO, the factors are divided into direct ones, which actually determine the possibility of MRO service units to improve economic parameters of their production management, and oblique factors, which can influence this possibility. The analysis of literature sources allows classification of factors of efficiency of MRO units work the next way:

Economic factors:

- equipment cost;

- moral depreciation of equipment;

- price level for MRO works;

- prices for replacement parts and repair \& maintenance materials;

- material reserves for repair \& maintenance needs;

- scientifically substantiated planning of repair works and expenses;

- quality of replacement parts and materials for repair \& maintenance needs; depreciation deductions.

Exploitation factors:

- equipment exploitation period;

- equipment technical condition;

- availability of replacement parts and material reserves for repair \& maintenance needs;

- operation conditions (vibration level, temperature, humidity level, etc.);

- qualification level of production staff;

- qualification level of maintenance staff.

Organization factors:

- organization form of MRO on the plant;

- equipment MRO management on the plant;

- in-process concentration and specialization of equipment MRO;

- interplant and interdepartmental concentration and specialization of equipment MRO;

- organization of material and moral incentive for maintenance staff;

- degree of labor mechanization for equipment MRO on the enterprise;

- system of quality assessment of equipment MRO works in the enterprise;

- assessment system of repair expenses efficiency.

Production-technical factors:

- equipment composition structure;

- physical wear of equipment;

- manufacturing technology of the produced goods;

- automatization degree of production;

- equipment maintenance and repair technologies.

Construction factors:

- selection of design solutions;

- selection of construction elements and materials. However, studied factors can have both positive and negative impact on efficiency of work of MRO units [23].

As V.M. Semenov noted, "all the variety of methods to raise the efficiency of work of technical maintenance units 
can be divided into two groups: the change in output volumes and the decrease in cost price" [24].

Among the economic factors, the role of depreciation deductions, the cost of production assets and the price level should be noted. What is more, efficiency of equipment MRO considerably depends on availability of replacement parts, their quality and cost. Creation of stocks, that are not economically substantiated, negatively impacts economic indicators of enterprise. Such stocks are usually formed because of poor quality of planning and mistakes in calculation of demand. On the other hand, underestimated material stock for repair and maintenance needs can cause a decrease in incomes of the enterprise due to an increase in equipment idle time during MRO and eventually it may result into drop of production output.

Exploitation factors greatly influence the volume of works on equipment MRO. The highest influence is exerted by operation life and technical state of equipment. Operation conditions, which include mechanical action (impact loads, vibrations, acceleration and work forces), temperature environment, humidity and particles in the air, are also of great importance. They usually affect the operation life and physical wear of equipment, leading to an increase in expenses on repair and maintenance of equipment. For example, metal machining equipment, operating in manufacturing shops of optical mechanics enterprises, gets worn two times faster than the same equipment on mechanical engineering factories. The reliability of equipment operation significantly depends on the qualification of repair and maintenance staff.

The efficiency of work of MRO service units depends on organization and management factors, such as organization form of MRO on the plant, organization of process management and control over MRO units and system of quality assessment of equipment MRO works in the enterprise.

Production-technical factors also play an important role in the system of equipment MRO efficiency. They include quality of the used production assets, equipment maintenance and repair technologies, and their compliance to new scientific and technical achievements. The changes in equipment composition structure and physical wear of equipment considerably affect the volume of works on equipment MRO [25].

The efficiency of equipment MRO is determined by construction factors in many ways. Selection of design solutions and materials should be noted, as they greatly affect the expenses on equipment operation. For example, the resistance of the rod of a large hammer of domestic heavy engineering plants lasts for about a week, and then it is required to manufacture the rod for replacement in a mechanical repair shop and carry out assembly and disassembly work on the hammer. The rod made from the rejected one is idle for more than a year. Resistance and costs are incomparable. But constructive factors are external factors that often cannot be controlled by the enterprise.

As the full list of factors influencing the efficiency feature is unknown, and the same can be said about the correlation ratio of particular factors to resulting efficiency, it is necessary to select the factors influencing the efficiency of equipment MRO very carefully. This is also reasonable due to the fact that one group of factors for a given level of management is objective, and the other is subjective. If availability of resources can be accepted as objective factor, the organization of its use has mainly subjective nature. The division of factors into subjective and objective is rather conditional, as objective factors are greatly influenced by the subjective ones. For example, labor resources should be reviewed as objective factor, but at the same time they depend on living environment (labor compensation, working conditions, and job prestige). Labor output growth is one of the main factors of increasing the efficiency of equipment MRO on the enterprise. However, this is a secondary factor, which is determined by availability of assets and energy, qualification of workers, degree of repair works specialization and quality characteristics of used equipment, organization of labor and a range of other primary factors.

One should consider diverse character and different speed of change of factors, affecting the efficiency. For example, growth of expenses on MRO service units can cause considerable decrease in labor input of repair works, increasing their quality, however, nobody knows for sure whether it results in downsizing the total expenses on equipment repair or not.

The task of factor analysis consists in studying the degree of influence of each factor on the efficiency of equipment MRO. Factor analysis applications are based on two schemes. The first scheme assumes the presence of already known factors, identified with specific indicators the factor of the type of production, the factor of the age of equipment, etc. It is only necessary to decide which of these factors affect the objects under study and in what combination. In the second scheme, the factors are unknown, it is necessary to identify them and determine the degree of their influence. It should be mentioned that almost all of the published theoretical and practical researches on factor analysis deal with solution of direct task. That is why we have decided that the first scheme is more appropriate for selection of factors, influencing the efficiency of equipment MRO. Besides, it is necessary to figure out the influence of in-process factors with available resources. Selection of the factors and indicators, expressing them, is the most important and responsible task and it is usually fulfilled in several stages. The first stage includes all factors, which can possibly affect the feature, characterizing the result. This stage should not have any limits during a priori analysis. It is necessary to study all factors, which influence the efficiency feature, by using different methods. Logical analysis does not ensure reliable determination of factors with close connection with the efficiency feature. Along with insignificant factors, one should also exclude from the system those factors that cannot be assessed quantitatively due to the lack of information necessary for this. Therefore, the selection of factors and features that characterize them should be 
continued using the methods of mathematical statistics (calculation of paired correlation coefficients and criteria for their reliability, partial correlation coefficients, and analysis of variance).

On the second stage comparative assessment is fulfilled and part of the factors is excluded by means of qualitative analysis combined with analysis of paired coefficients and correlation indices and an assessment of their significance. The matrix of paired correlation coefficients simplifies this work; it allows assessment of correlation ratio of each factor both to the efficiency feature and the other factors. If there is extreme correlation between the factors, a part of them should be excluded, until there are no correlation coefficients exceeding 0,8 . The matrix of paired coefficients simplifies selection of indicator for expression of one or another factor in case of introduction of several indicators in the model. The factor, which has closer correlation to the efficiency feature, rather than other factors, should be preferred. If the correlation ratios of a number of factors to the efficiency feature turn out to be high, the decision on the preference of the factor can be postponed to the next stage of selection. On this stage various versions of the multivariate model are built. It should be considered that low coefficients for linear correlation may not reflect the real value of nonlinear correlation.

The final stage of factors selection is fulfilled with application of different variants of multifactor models, in which the form of the relationship of factors with an efficiency feature is identified. At this stage, the significance of the regression coefficients is checked. This completes the selection of factors in the process of multistep regression analysis. After solving the model and evaluating the significance of all regression coefficients, those factors for which the coefficients are insignificant are excluded from the equation. The process of excluding factors should be continued until all the regression coefficients in the regression equation are significant.

Efficiency feature of equipment MRO should be a logical consequence of influence of factors and have correlation with the factors.

During regression and correlation analysis it is necessary to study the relationships both in multifactor model and paired correlation relationships. In the equation of multilinear regression the coefficients at $X i$ show how the efficiency feature averagely changes with an increase in the corresponding factor by one, while the other factors included in the regression equation remain unchanged. The coefficients of paired regressions show how efficiency feature changes with increase of the given factor by one with simultaneous corresponding change in other factors correlated with it.

The difference between the values of parameters in the equations of multiple and paired regressions is explained by the existence of dependence between the factors. The coefficient in the equation of paired regression characterizes not the effect from the changes in given factor itself, but its relative effect. It expresses not only pure influence of given factor on efficiency factor, but influence of other factors, correlated with it and affecting the efficiency feature through that factor. The coefficients at $X i$ in multiple regression equation should be eliminated, i.e. freed from the influence of other factors in the equation. Elimination is made by different methods - chain substitutions, methods of differences and equity participation, balance and economic-mathematical methods (sampling method, calculation of variation, correlation, regression and variance analysis, linear programming, using methods of queuing theory, etc.). The more fully the factors are represented in the multiple regression equation, the more accurately the regression coefficients express the net efficiency of the factors. At the same time, the effect of each factor included in the multiple regression equation is cleared from the influence of factors included in the equation, though it is not cleared from the influence of factors not presented in the equation

Taking into account the mentioned above, there is a question: as all the factors, influencing the efficiency of equipment MRO are interrelated and interdependent, can there really be a phenomenon in which proportionality between the factors remains, if one of them changes by one unit, while the others remain unchanged? That is why multiple regression coefficients should be compared with paired correlation coefficients. The forms of relations should be checked on the stage of analysis of paired correlation by comparing the data from several models with different relation form.

\section{RESULTS}

Selection of factors and features, expressing them is made on the final stage by means of multistep regression analysis and analysis of the results of consequent interpretations with the use of expert evaluation method, which allows reliable identification of amount and value of factors and their classification. As classification of factors can be made by experts with subjective approach, some of the researchers make the conclusion that "in current conditions the application of method of factor analysis of state and development tendencies of production economics does not fully satisfy the task of increasing the production efficiency" [4, p.51]. In our opinion, such categorical conclusion is not perfect. Indeed, expert evaluation method has certain disadvantages because of possibility of subjective approach of particular experts. However, the advantages of factor analysis prevail this possible disadvantage and the use of this method for determination of major factors, influencing the efficiency of equipment $\mathrm{MRO}$ on industrial enterprises in current conditions is correct and reasonable.

Studying the mentioned factors, it should be assumed that there is as minimum one more important factor, which forms the efficiency of activities in equipment MRO. Such factor, as we think, is the level of economic autonomy of service units, carrying repair functions [24]. The existence of this factor is considered fundamental by a range of authors $[4,8,26,27]$. Thus, on the base of research, carried out on materials of repair, instrumental, 
energetic and transport services of several mechanical engineering plants, Z.B. Khmelnitskaya has made the following conclusion. "The choice of organization forms is fundamental in the decision-making technique during organization of system of production and technical service, as they bring the certain changes in volumes, nomenclature of operations and services, organization structure of manufacturing and composition of management structure of service units" [27].

In our opinion, the presence of such factor as level of economic autonomy of a subject, fulfilling repair works is also conditioned by other reasons:

1. Currently there are many different ways of equipment MRO organization, they can be fully or partly autonomous subjects (MRO companies in holding and outsourcing independent companies). Organization method results in differences in management systems and other different aspects, which form subject behavior on market.

2. An increase in economic autonomy of a subject results in growth of personal interest of workers, which in turn leads to a decrease in expenses and an increase in labor output including optimization of all types of resources [28].

To assess the influence of all identified factors on the efficiency of work of MRO service units expert opinion poll has been carried out. The expert group included employees of several mechanical engineering enterprises and one specialized inter-holding company producing MRO equipment:

- deputy director for production - 1 person,

- chief engineers -2 people,

- chief mechanics -4 people,

- chief power engineers -3 people,

- chief metrologists -3 people,

- heads of power engineering shops -2 people,

- shop foremen -6 people.

During the first stage of the poll the experts, using paired comparison method, have divided all factors into three groups by degree of influence on efficiency.

First group of factors, defined as factors, having decisive influence on formation of efficiency, includes the following:

- system of management over MRO activities;

- economic state of the enterprise;

- operation life and wear of the equipment to be repaired;

- improvement in organization of service production;

- level of economic autonomy of MRO company;

- prices for replacement parts and repair materials;

- operation conditions of equipment (temperature environment, particles in the air, vibrations and etc.);

- qualification level of production workers;

- qualification level of repair workers;

- interplant and interdepartmental concentration and specialization of equipment MRO;

- in-process concentration and specialization of equipment MRO;

- cooperation of repair works;
- equipment MRO technologies.

The influence of the given group of factors on the efficiency value is estimated as $30-50 \%$ by different experts. Explanation of such factor as degree of economic autonomy, based on studying literature sources and analysis of expert opinions looks the next way:

- possibility to allocate the profit independently. Such profit allocation will lead to an increase in staff wages and improvement of structure of equipment stock, used in MRO;

- possibility to form quotation for MRO services independently. The experts have noted that due to high indirect costs large and medium mechanical engineering enterprises are not able to quote competitive prices, which causes losses of orders with simultaneous underload of maintenance staff;

- possibility to design and adapt organization structure independently. The experts proved this statement by examples of equipment downtimes due to inefficient transfer of material values, information, distribution of repair works among personnel.

The second group of factors, named as factors, having medium influence on formation of efficiency, includes the next factors:

- complexity and labor input of repair works;

- the use of operational time;

- stimulation of repair personnel;

- provision of MRO service units with equipment;

- availability of material reserves for repair \& maintenance needs;

- improvement of technology of ancillary processes;

- mechanization and automatization of labor of maintenance workers;

- improvement of servicing technologies, compliance with technological discipline and exploitation rules for repaired equipment.

The influence of this group of factors has been estimated by the experts in the range of $5-29 \%$.

The third group of factors, defined as the least important for MRO efficiency, includes:

- the state and planning of accounting;

- structure and volume of products manufactured by the enterprise, production program;

- decrease in cost price of main production;

- production assets loading;

- equipment cost;

- depreciation deductions.

The influence of this group of factors is evaluated as up to $5 \%$.

\section{CONCLUSION}

The results collected in this work have shown that with the purpose of additional specification of the priority factors it is reasonable to analyze only complex factors from the first group:

1. Organization factors:

- method of organization of work of equipment MRO service (improvement of service production organization); 
- qualification level of production workers;

- qualification level of repair workers;

- interplant and interdepartmental concentration and specialization of equipment MRO;

- in-process concentration and specialization of equipment MRO;

- cooperation of repair works;

- level of economic autonomy of MRO enterprise.

2. Economic factors:

- economic state of the enterprise;

- prices of replacement parts and repair and maintenance materials.

3. Production-technical factors:

- operational life and wear of equipment to be repaired;

- operation conditions of equipment (temperature environment, particles in the air, vibrations and etc.);

- equipment MRO technologies.

The content of factor "economic state of the enterprise" is indicative of financial component, that determines its profitability and solvency. Such statement allows addition of financial component to the formulation of this factor and define it as "financial and economic state of the enterprise"

During the second stage of expert opinion poll, they determined the importance of each factor, obtained in the first stage, in the efficiency of work of equipment MRO service units.

Identification of the most meaningful factors will ensure formation of high-efficiency MRO service in short time. The narrowing of range of factors will lead to removing of specific restrictions, practical fulfillment of which is connected with growth of labor input and increase in expenses.

The results of the first stage of the poll are shown in Table 2.

Table 2

Importance of factors, influencing the efficiency of work of MRO services

\begin{tabular}{|l|c|}
\hline \multicolumn{1}{|c|}{ Factor } & $\begin{array}{c}\text { Factor } \\
\text { importance }\end{array}$ \\
\hline $\begin{array}{l}\text { 1. Method of organization of work of } \\
\text { equipment MRO service }\end{array}$ & 18.3 \\
\hline $\begin{array}{l}\text { 2. Level of economic autonomy of MRO } \\
\text { enterprise }\end{array}$ & 20.5 \\
\hline $\begin{array}{l}\text { 3. Market situation of enterprise en- } \\
\text { gaged in equipment repair }\end{array}$ & 19.6 \\
\hline $\begin{array}{l}\text { 4. Prices of replacement parts and re- } \\
\text { pair and maintenance materials }\end{array}$ & 10.1 \\
\hline $\begin{array}{l}\text { 5. Operational life and wear of equip- } \\
\text { ment to be repaired }\end{array}$ & 9.4 \\
\hline 6. Operation conditions of equipment & 10.9 \\
\hline 7. Equipment MRO technologies & 11.2 \\
\hline In total & 100 \\
\hline
\end{tabular}

According to the results of expert opinion poll, it can be noted that the main factors, forming the efficiency of work of MRO service units are:

- method of organization of work of equipment MRO service;
- level of economic autonomy of MRO enterprise;

- financial and economic state of MRO enterprise;

- the degree of repair complexity of production equipment.

\section{REFERENCES}

[1] Z.B. Khmelnitskaya. Organizational and economic problems of increasing the efficiency of production and technical services. Ural University. 205 p. 1987.

[2] A.N. Vodolazov. Economic assessment of the activities of auxiliary production facilities of the enterprise: methodology and tools. DonSTU. 22 p. 2002.

[3] V.N. Goncharov, O.A. Burbelo, A.I. Vavin. The efficiency of the production infrastructure of enterprises. LOT. $164 \mathrm{p}$. 1994.

[4] L.N. Dragun. Improving the economic management of repair production (theory and practice). Irkutsk University Publ., 140 p. 1985.

[5] R.N. Kolegaev, K.I. Melnikova, B.I. Krivoberets. Efficiency of the repair service of the enterprise and association. Technique, 160 p. 1976.

[6] G.A. Morgun. Efficiency management of enterprises in the conditions of reforming the electric power industry. UPI, 192 p. 2004.

[7] V.K. Myltsev. Questions of increasing the organizational and technical level and efficiency of repair production. UPI. 25 p. 1981.

[8] U.F. Nasibullin. Interplant management of the repair service. SPb GIEA. 17 p. 1997.

[9] S.F. Pokropivny. Efficiency of car repair. Tekhnika, 256 p. 1975.

[10] R.R. Stepanova. Methods and tools for increasing the economic efficiency of repair services of chemical enterprises. D. Mendeleev University of Chemical Technology of Russia. 145 p. 2004.

[11] N.G. Chumachenko. Problems of organizing the effective functioning of auxiliary production in mechanical engineering. IEM USSR Academy of Sciences, 30 p. 1979.

[12] J. Tabor. Ranking of management factors for safe maintenance system based on Grey Systems Theory. Production Engineering Archives. 2021, 27(3), pp. 196-202, doi: 10.30657/pea.2021.27.26

[13] K. Kowalik, D. Klimecka-Tatar. The process approach to service quality management. Production Engineering Archives. issue 18, pp. 31-34 doi:10.30657/pea.2018.18.05. 2018.

[14] R. Ulewicz, M. Mazur. Economic aspects of robotization of production processes by example of a car semi-trailers manufacturer, Manufacturing Technology. 19(6), pp. 1054-1059, doi: 10.21062/ujep/408.2019/a/12132489/MT/19/6/1054. 2019.

[15] J. Furman. Work Safety Improvement Within Autonomous Maintenance. Multidisciplinary Aspects of Production Engineering MAPE 2020, vol. 3, issue 1, pp. 161-171 https://doi.org/10.2478/mape-2020-0014. 2020.

[16] P. Gackowiec. General overview of maintenance strategies - concepts and approaches Multidisciplinary Aspects of Production Engineering MAPE 2019, vol. 2, issue 1, https://doi.org/10.2478/mape-2019-0013. 2019.

[17] B. Al-Najjar, \& I. Alsyouf, I. Selecting the most efficient maintenance approach using fuzzy multiple criteria decision making. International Journal of Production Economics, 84(1), pp. 85-100. doi: 10.1016/S09255273(02)00380-8.10. 2003. 
[18] H. Cherkaoui, K.T. Huynh, \& A. Grall. On the Assessment of Performance and Robustness of Condition-Based Maintenance Strategies. IFAC-PapersOnLine, Elsevier B.V. 49(12), pp. 809-814. 2016. doi: 10.1016/j.ifacol.2016.07.874.10.1016.

[19] J. Mikler. Life Cycle Costing Used for Justifying Transition to Predictive Maintenance Strategies. Journal of Machine Engineering, 11(4), 2011. pp. 49-58.

[20] J. Tabor. Maintenance management and occupational safety in manufacturing organizations. Polish Journal of Management Studies, 10 (2), pp. 225-235. 2014.

[21] E.C. Özcan, S. Ünlüsoy, \& T. Eren. A combined goal programming - AHP approach supported with TOPSIS for maintenance strategy selection in hydroelectric power plants. Renewable and Sustainable Energy Reviews, Elsevier Ltd, 78 (May 2016), pp. 1410-1423. doi: 10.1016/j.rser.2017.04.039. 2016.

[22] L. Oubahman, S. Duleba. Review of PROMETHEE method in transportation, Production Engineering Archives. 27(1), pp. 69-74. doi: 10.30657/pea.2021.27.9. 2021.

\section{Marek Krynke}

ORCID ID: 0000-0003-4417-1955

Czestochowa University of Technology

ul. J.H. Dąbrowskiego 69, 42-201 Częstochowa, Poland

e-mail: marek.krynke@pcz.pl

\section{Tatiana Nikolaevna Ivanova}

ORCID ID: 0000-0003-2284-2949

Tchaikovsky Branch

"Perm National Research Polytechnic Institute", Russia

Federal State Budgetary Institution of Science

"Udmurt Federal Research Center of the Ural Branch

of the Russian Academy of Sciences",

Institute of Mechanics, Russia

e-mail: tatnic2013@yandex.ru

\section{Nikolay Fedorovich Revenko}

ORCID ID: 0000-0003-3423-9039

Academy of Economic Sciences of Ukraine

Academy of Military Sciences of the Russian Federation

Izhevsk State Technical University

named after M.T. Kalashnikov, Russia

Autonomous Noncommercial Organization

"Study Accreditation Center"

Sarapul, Russia
[23] D.L. Krutikhin. V.E. Lyalin. Application of queuing systems to improve the efficiency of maintenance and equipment repair services at an industrial enterprise//Mathematical models and information technologies in the organization of production. no. 2 (23). pp. 48-52. 2011.

[24] V.M. Semyonov. Problems of the efficiency of maintenance of mechanical engineering production. UPI. 40 p. 1978.

[25] K. Knop. Analysing the machines working time utilization for improvement purposes. Production Engineering Archives. 2021, 27(2), pp. 137-147, doi: 10.30657/pea.2021.27.18

[26] N.F. Revenko. The economic mechanism in repair production (on the example of industrial associations and enterprises of the mechanical engineering industry). IEP AN UkrSSR. 351 p. 1991.

[27] Z.B. Khmelnitskaya. Organization and management of production and technical maintenance of mechanical engineering enterprises. 1992.

[28] M. Krynke. Management optimizing the costs and duration time of the process in the production system. Production Engineering Archives. 2021, 27(3), pp. 163-170, doi: 10.30657/pea.2021.27.21 